\title{
Operative strategies to reduce cerebral embolic events during on- and off-pump coronary artery bypass surgery: A stratified, prospective randomized trial
}

\author{
Michael E. Halkos, MD, MSc, ${ }^{a}$ Aaron Anderson, MD, ${ }^{b}$ Jose Nilo G. Binongo, PhD, ${ }^{c}$ \\ Anthony Stringer, PhD, ${ }^{\mathrm{d}}$ Yi Lasanajak, MSPH, ${ }^{\mathrm{c}}$ Vinod H. Thourani, MD, ${ }^{\mathrm{a}}$ Omar M. Lattouf, MD, ${ }^{\mathrm{a}}$ \\ Robert A. Guyton, MD, ${ }^{a}$ Kim T. Baio, MSN,${ }^{a}$ Eric Sarin, MD,${ }^{e}$ William B. Keeling, MD, ${ }^{a}$ \\ N. Renee Cook, BSN, ${ }^{\mathrm{a}}$ Katherine Carssow, MPH, ${ }^{\mathrm{a}}$ Alexis Neill, MSN, ${ }^{\mathrm{a}}$ Kathryn E. Glas, MD, ${ }^{\mathrm{f}}$ and \\ John D. Puskas, MD ${ }^{g}$
}

\section{ABSTRACT}

Objective: To determine the impact of different aortic clamping strategies on the incidence of cerebral embolic events during coronary artery bypass grafting (CABG).

Methods: Between 2012 and 2015, 142 patients with low-grade aortic disease (epiaortic ultrasound grade I/II) undergoing primary isolated CABG were studied. Those undergoing off-pump CABG were randomized to a partial clamp $(n=36)$ or clampless facilitating device $(\mathrm{CFD} ; \mathrm{n}=36)$ strategy. Those undergoing onpump CABG were randomized to a single-clamp $(n=34)$ or double-clamp ( $\mathrm{n}=36$ ) strategy. Transcranial Doppler ultrasonography (TCD) was performed to identify high-intensity transient signals (HITS) in the middle cerebral arteries during periods of aortic manipulation. Neurocognitive testing was performed at baseline and 30-days postoperatively. The primary endpoint was total number of HITS detected by TCD. Groups were compared using the Mann-Whitney $U$ test.

Results: In the off-pump group, the median number of total HITS were higher in the CFD subgroup (30.0; interquartile range [IQR], 22-43) compared with the partial clamp subgroup (7.0; IQR, $0-16 ; P<.0001)$. In the CFD subgroup, the median number of total HITS was significantly lower for patients with 1 CFD compared with patients with $>1$ CFD (12.5 [IQR, 4-19] vs 36.0 [IQR, 25-47]; $P=.001)$. In the on-pump group, the median number of total HITS was 10.0 (IQR, 3-17) in the single-clamp group, compared with 16.0 (IQR, 4-49) in the double-clamp group $(P=.10)$. There were no differences in neurocognitive outcomes across the groups.

Conclusions: For patients with low-grade aortic disease, the use of CFDs was associated with an increased rate of cerebral embolic events compared with partial clamping during off-pump CABG. A single-clamp strategy during on-pump CABG did not significantly reduce embolic events compared with a doubleclamp strategy. (J Thorac Cardiovasc Surg 2017;154:1278-85)

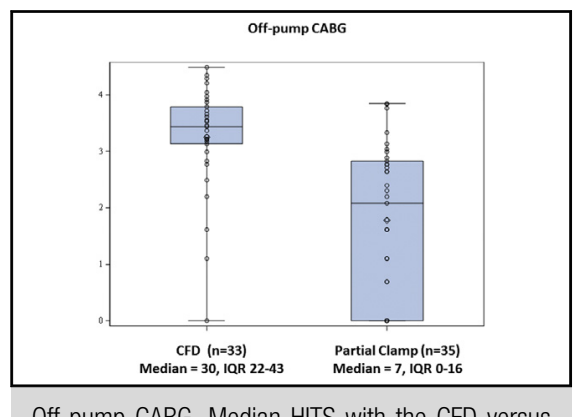

Off-pump CABG. Median HITS with the CFD versus partial clamp.

\section{Central Message}

Patients with low-grade aortic disease undergoing off-pump CABG had more embolic events with CFDs than with partial clamping. Onpump patients had comparable results with single or double clamping.

\section{Perspective}

Aortic clamping during CABG surgery is associated with cerebral atheroembolism, which is likely responsible for increased risk of periprocedural stroke in patients undergoing CABG. The findings of this study support the use of traditional clamping methods during on- or off-pump CABG for patients with low-grade aortic disease.

See Editorial Commentary page 1286.
From the ${ }^{\mathrm{a}}$ Division of Cardiothoracic Surgery, Departments of ${ }^{\mathrm{b}}$ Neurology, ${ }^{\mathrm{d}}$ Rehabilitation Medicine, and ${ }^{\mathrm{f}}$ Anesthesiology, ${ }^{\mathrm{c}}$ Rollins School of Public Health, Emory University School of Medicine, Atlanta, Ga; ${ }^{\mathrm{e}}$ Department of Cardiothoracic Surgery, Inova Fairfax Healthcare System, Falls Church, Va; and ${ }^{g}$ Department of Cardiothoracic Surgery, Mount Sinai University School of Medicine, New York, NY.

This work was supported by the National Heart, Lung, and Blood Institute (Grant 5K23HL105892-05) and the National Center for Advancing Translational Sciences (Grant UL1TR000454). The content is solely the responsibility of the authors and does not necessarily represent the official views of the National Institutes of Health. Registered with ClinicalTrials.gov (NCT01502683).
Read at the 96th Annual Meeting of The American Association for Thoracic Surgery, Baltimore, Maryland, May 17, 2016.

Received for publication Nov 10, 2016; revisions received March 8, 2017; accepted for publication April 10, 2017; available ahead of print July 18, 2017.

Address for reprints: Michael E. Halkos, MD, MSc, Division of Cardiothoracic Surgery, Emory University School of Medicine, 550 Peachtree St, NE, 6th floor MOT, Atlanta, GA 30308 (E-mail: mhalkos@emory.edu). 0022-5223/\$36.00

Copyright (c) 2017 by The American Association for Thoracic Surgery http://dx.doi.org/10.1016/j.jtcvs.2017.04.089 

Abbreviations and Acronyms
ANOVA $=$ analysis of variance
$\mathrm{CABG}=$ coronary artery bypass grafting
CFD = clampless facilitating device
CNSVS $=$ CNS Vital Signs
HITS = high-intensity transient signals
$\mathrm{IQR}=$ interquartile range
RBANS $=$ Repeatable Battery for
Neuropsychological Status
$\mathrm{TCD}=$ transcranial Doppler ultrasonography

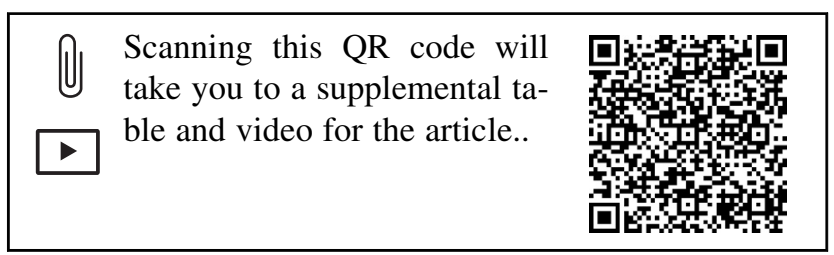

Despite advances in no-aortic-touch multiarterial revascularization, extracorporeal perfusion techniques, and offpump approaches to minimizing adverse neurologic events, these events remain a leading cause of morbidity associated with coronary artery bypass grafting surgery (CABG). Adverse neurologic events are frequently attributed to atheroembolism resulting from aortic manipulation, ${ }^{1}$ which can occur at any part of the procedure, including aortic clamping, cannulation insertion and removal, and initiation of bypass. Thus, it would seem intuitive that minimizing aortic manipulation would result in less cerebral embolism. Although this is one of the potential benefits of off-pump CABG, off-pump approaches frequently use some degree of aortic manipulation for the construction of proximal aortocoronary anastomoses. ${ }^{2,3}$

Transcranial Doppler ultrasonography (TCD) has been used to detect high-intensity transient signals (HITS) in the middle cerebral arteries. This technique is highly sensitive for cerebral microembolization, but the association with clinical outcomes and neurocognitive dysfunction has not been demonstrated. Most of the studies published to date have been observational in nature and thus subject to bias and confounding, whereas others have not examined the spectrum of proximal aortic strategies with different revascularization options. Thus, the purpose of this randomized trial was to compare the impact of different aortic manipulation strategies on the number of cerebral embolic events occurring during CABG.

\section{METHODS}

\section{Trial Design and Oversight}

This trial was a randomized, single-center trial with 7 participating surgeons with expertise in both off-pump (each surgeon having performed at least 100 off-pump cases) and on-pump CABG, as well as in the use of clampless facilitating devices (CFDs) for constructing proximal aortocoronary anastomoses. Data collection and management were handled by the Cardiothoracic Center for Clinical Research at Emory University. The Institutional Review Board of Emory University reviewed and approved the study. The trial was monitored by an independent Data and Safety Monitoring Board.

\section{Study Population}

Patients scheduled for elective or urgent, first-time multivessel sternotomy CABG were eligible for enrollment. All patients underwent a routine and standardized preoperative evaluation by the attending surgeon and a mid-level provider, including carotid artery ultrasound. Exclusion criteria included a history of preoperative stroke, preoperative or concomitant carotid endarterectomy, stenting, or known hemodynamically $(>80 \%)$ significant stenosis; known left ventricular or left atrial thrombus; planned concomitant cardiac surgical procedure, salvage or emergency CABG, reoperative cardiac surgery, $\mathrm{CABG}$ with no planned aortocoronary proximal anastomoses, or the presence of a preoperative intra-aortic balloon pump; and unwillingness or inability to provide consent. All enrolled patients provided written informed consent.

\section{Randomization and Treatment}

The study was designed to study and compare the effects of different strategies of construction of proximal anastomoses; it was not designed to compare off- versus on-pump CABG. The decision to perform off- versus on-pump CABG was at the discretion of the operating surgeon. Randomization occurred intraoperatively after completion of sternotomy and epiaortic ultrasonography. Only patients with low-grade ascending aortic disease (grade I-II; Table 1) by epiaortic ultrasound were randomized, regardless of whether an off- versus on-pump approach was selected by the operating surgeon. ${ }^{4}$ Specifically, patients selected for off-pump CABG were randomized 1:1 to have proximal aorto-coronary anastomoses performed with a partial-occluding clamp or with a CFD (Heartstring Device; Maquet Cardiovascular, San Jose, Calif). Patients selected for on-pump CABG were randomized 1:1 to have proximal aorto-coronary anastomoses performed with a single clamp or a double clamp (cross-clamp for cardioplegic arrest and partial- clamp for proximal anastomoses). A randomized block design was used with blocks of 8 ; after epiaortic ultrasound confirmed grade I-II aortic disease, the randomization assignment was revealed via an opaque envelope by the research coordinator. Patients who were determined intraoperatively to have grade III-V ascending aortic disease by epiaortic ultrasound were excluded from randomization and the study. At an $\alpha$ level of 0.05 , there would be $80 \%$ power to detect a treatment difference, if it exists, of 40 HITS with 31 patients per group using the Mann-Whitney $U$ test. With an attrition rate of $10 \%$ due to dropouts and possible technical problems, the plan was to recruit 34 patients in each group.

\section{Surgical Technique}

All patients underwent sternotomy. Routine left internal mammary artery harvest was performed in all cases. Saphenous vein grafts were harvested using endoscopic techniques. Patients undergoing on-pump CABG underwent standard ascending aortic and right atrial cannulation for cardiopulmonary bypass. In patients randomized to a single-clamp strategy, proximal aortocoronary anastomoses were performed before release of the cross-clamp. In patients randomized to a double-clamp strategy, the cross-clamp was released after distal anastomoses, followed by application of a partial clamp for the construction of proximal anastomoses.

In patients undergoing off-pump CABG, distal anastomoses were performed using cardiac positioning and stabilizing devices. In patients randomized to the partial clamp subgroup, proximal aorto-coronary anastomoses were performed using a partial clamp on the ascending aorta. 
TABLE 1. Epiaortic ultrasound grading system used at Emory University

\begin{tabular}{lll}
\hline $\begin{array}{c}\text { Ultrasound } \\
\text { grade of } \\
\text { ascending aorta }\end{array}$ & $\begin{array}{c}\text { Severity } \\
\text { (atheroma } \\
\text { thickness) }\end{array}$ & \multicolumn{1}{c}{ Description } \\
\hline 1 & Normal & Intimal thickness $<2 \mathrm{~mm}$ \\
\hline 2 & Mild & $\begin{array}{c}\text { Mild (focal or diffuse) intimal } \\
\text { thickening of 2-3 mm }\end{array}$ \\
\hline 3 & Moderate & $\begin{array}{c}\text { Atheroma }<3-5 \mathrm{~mm} \text { (no mobile/ } \\
\text { ulcerated components) }\end{array}$ \\
\hline 4 & Severe & $\begin{array}{c}\text { Atheroma }>5 \text { mm (no mobile/ } \\
\text { ulcerated components) }\end{array}$ \\
\hline 5 & Complex & $\begin{array}{c}\text { Grade 2, 3, or 4 atheroma plus mobile } \\
\text { or ulcerated components }\end{array}$ \\
\hline
\end{tabular}

In patients randomized to the CFD subgroup, proximal anastomoses were performed using the Heartstring device.

\section{TCD}

All patients underwent TCD evaluation to detect cerebral embolic signals during all periods of aortic manipulation using the Compumedics DWL system and QL software (Compumedics, Singen, Germany). In the on-pump group, TCD monitoring measurements were recorded at (1) cannulation; (2) initiation of cardiopulmonary bypass; (3) aortic crossclamping; (4) removal of the aortic cross-clamp; (5) application of a partial clamp (double-clamp group); (6) removal of the partial clamp (doubleclamp group); (7) removal of the aortic cannula. For the off-pump group, TCD monitoring measurements were recorded at placement and removal of each CFD, or placement and removal of the partial clamp. The DWL system is a fully digital system that uses an automated event detector to identify HITS and is powered by the Doppler M-mode. The Doppler M-mode simultaneously receives and analyzes Doppler signals from a predefined range of depths. This allows for verification of emboli detection when an embolus passes through various depths. Microemboli traveling along an insonated vessel will appear as HITS on the TCD spectrum. The system uses a $2.0-\mathrm{MHz}$ probe with a power range of 20 to $100 \mathrm{~mW}$. Initially, an adequate temporal window was confirmed by locating intracranial arterial signals. The right middle cerebral artery was insonated at a depth of 50 to $65 \mathrm{~mm}$. The middle cerebral artery was verified through visualization of the depth and flow direction. The spectra from each period of insonation were saved to the hard drive of the computer. The number and timing of HITS were monitored and recorded by dedicated research coordinators who were trained and experienced in TCD (Video 1). Differentiation between solid and gaseous HITS was not done, because the overall clinical accuracy of dual frequency and frequency modulation analyses were insufficient to accurately separate gas from solid emboli. ${ }^{5-7}$

All TCD data were reviewed and adjudicated by a staff neurologist at Emory University with expertise in TCD ultrasonography who was blinded to the treatment group. False-positive recordings that were recorded as HITS by the software were identified by our neurologist and excluded from the analysis.

\section{Neurocognitive Assessment}

Neurocognitive function was measured preoperatively and at 30 days postoperatively. Selection of the test battery likely to be sensitive to cognitive deficits in a cardiac surgery population was guided by previous studies of neuropsychological outcomes following cardiac surgery, ${ }^{8,9}$ as well as by research in our own laboratory. ${ }^{10}$ For this assessment, CNS Vital Signs computerized neurocognitive testing (CNSVS; CNS Vital Signs, Morrisville, NC) was used for the majority of patients. The

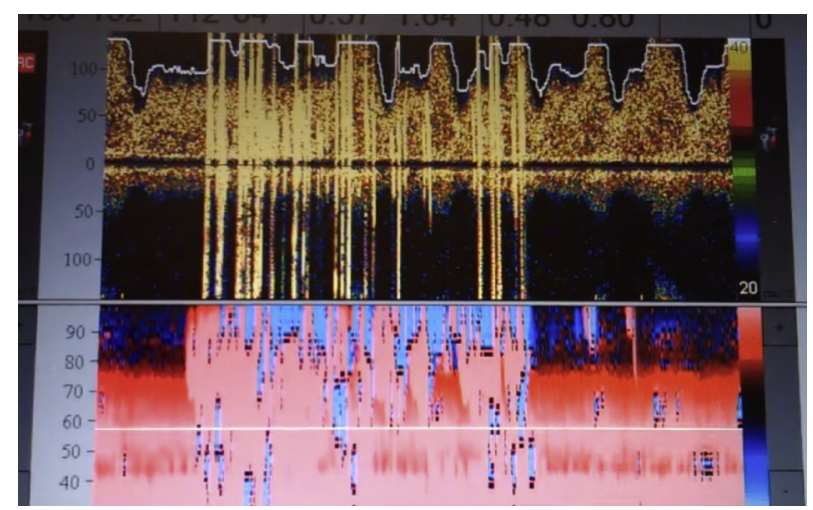

VIDEO 1. Video of actual recording obtained with TCD measurement during clamp removal. The sounds interspersed during the pulse wave recordings are recorded as HITS by the computerized software program. Video available at: http://www.jtcvsonline.org/article/S0022-5223(17) 31226-6/addons.

neuropsychological test was changed from the Repeatable Battery for Neuropsychological Status (RBANS) test to CNSVS after the first 25 randomized patients to improve standardization of testing through computerized administration. Eliminating the handwritten RBANS test reduced potential variations in test administration among nurse coordinators. Neuropsychological testing was administered by clinical coordinators and scored by either computer (CNSVS) or neuropsychological technicians (RBANS) under the supervision of an experienced neuropsychologist. The CNSVS scoring algorithm detects normatively rare scores, which could reflect actual poor cognitive performance but also could be due to poor effort, subject distractibility, or other factors that could potentially invalidate the scores. Because we could not distinguish among these causes of normatively out-of-range scores, we excluded all such potentially invalid scores from our analyses.

The change from RBANS to CNSVS required us to exclude the neuropsychological data on individual RBANS subtests from the initial 25 subjects, because those scores were not on a comparable scale as the CNSVS subtests. This reduced the sample size for which subtest neuropsychological data were available and reduced the statistical power. Nonetheless, the improved standardization of test administration likely increased the reliability of available data. The RBANS and CNSVS both include a total score reflecting overall neuropsychological performance that is scaled comparably across the 2 batteries. We were able to include either the RBANS or CNSVS total score in a single analysis of overall neuropsychological performance across groups.

\section{Statistical Analysis}

TCD outcomes. For power analysis, the expected number of HITS in each subgroup was estimated to be 50 for CFD, 90 for partial clamp, 100 for single clamp, and 160 for double clamp based on pilot data ${ }^{11}$ for off-pump CABG as well as on previously published reports for on-pump CABG. ${ }^{12}$ For the off-pump group, given a significance level of 0.05 , we would have $80 \%$ power to detect a treatment difference of 40 HITS with 31 patients per subgroup using the Mann-Whitney $U$ test. Assuming an attrition rate of $10 \%$ due to dropouts and technical problems, 34 patients were needed in both the CFD and partial-clamp subgroups. For the on-pump group, assuming a significance level of 0.05 , we would have $80 \%$ power to detect a treatment difference of 50 HITS with 31 patients per subgroup. Assuming an attrition rate of $10 \%$ due to dropouts and technical problems, 34 patients would be needed in both the single-clamp and double-clamp subgroups.

The same data analyses were performed in the CFD and partial-clamp subgroups for off-pump CABG and for single-clamp and double-clamp 
subgroups for on-pump CABG. Numeric variables were summarized using mean \pm standard deviation or median and interquartile range (IQR), as appropriate. Categorical variables were summarized as count (percentage). Group averages were compared using the Student $t$ test or Mann-Whitney $U$ test, as appropriate). Group proportions were compared using the $\chi^{2}$ test or Fisher's exact test, as appropriate. The Mann-Whitney $U$ test was used to assess the difference in the average number of HITS between groups. To graphically compare HITS distributions, boxplots were drawn after logtransforming the number of HITS. Log transformation compresses the scale for high values and stretches the scale for low values and provides a better visual comparison between 2 right-skewed distributions. Comparative analyses of the total number of HITS between the CFD and partial-clamp subgroups and between the single-clamp and double-clamp subgroups were intention-to-treat. Secondary questions comparing, for example, 1 CFD and $>1$ CFD were as-treated. Tests of hypotheses were 2 -sided, and a significance level of 0.05 was used throughout. All data analyses were performed using SAS 9.4 (SAS Institute, Cary, NC).

Neurocognitive testing. Invalid CNSVS scores on given variable were excluded from analysis. All planned comparisons were conducted on pretreatment and posttreatment raw and age-adjusted scaled scores, as well as on change scores (pretreatment score subtracted from posttreatment score).

\section{RESULTS}

\section{Enrollment and Patient Characteristics}

Between 2012 and 2015, 193 patients were enrolled and 142 patients underwent randomization. For the patients enrolled, the main reasons for exclusion were the inability to obtain a TCD signal over the middle cerebral artery and a grade III-V aorta on epiaortic ultrasound (Figure 1). In the off-pump group, 72 patients were randomized to have proximal aortocoronary anastomoses performed using either a CFD or a partial clamp. In the on-pump group, 70 patients were randomized to either a single cross-clamp or a double-clamp strategy for construction of aortocoronary proximal anastomoses. Baseline characteristics were similar across the groups (Table 2). For randomized patients in the on-pump group, all patients received the treatment that they were assigned. For all patients in the single-clamp subgroup, no additional clamping was done after release of the cross-clamp. All patients in the double-clamp subgroup received only 1 application of the cross-clamp and only 1 application of the partial clamp. For the off-pump group, 2 patients who were randomized to the partial clamp subgroup received a CFD, and 2 patients who were randomized to the CFD subgroup received a partial clamp. The 30-day postoperative follow-up was completed in 129 patients (91\%).

\section{Clinical Outcomes}

No 30-day mortality, postoperative myocardial infarction, or deep sternal infection occurred in any group. Superficial sternal infections occurred in 3 patients $(8.3 \%)$ in the partial-clamp subgroup and in 2 patients $(5.6 \%)$ in the

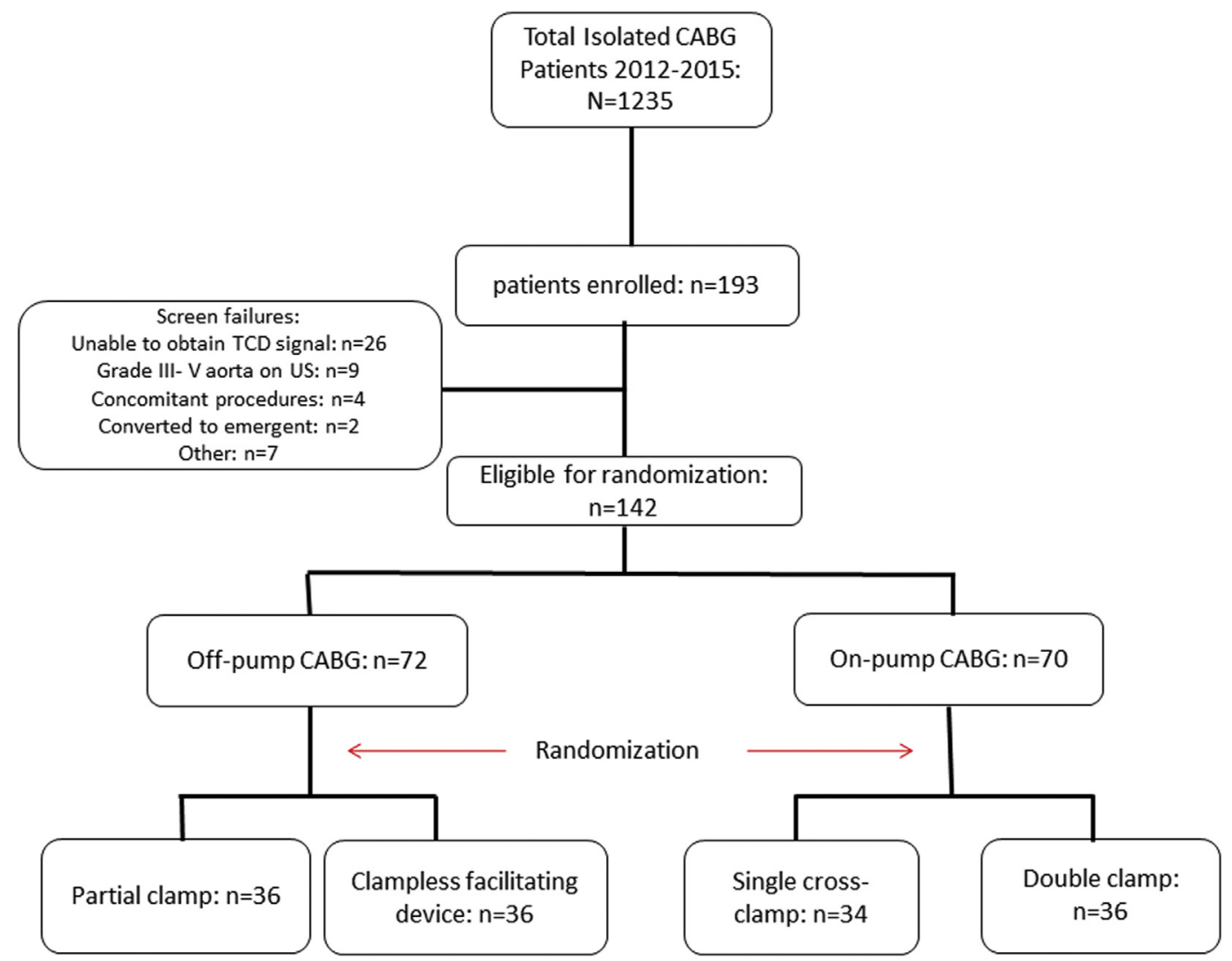

FIGURE 1. CONSORT diagram of trial enrollment, randomization, and treatment received. $C A B G$, Coronary artery bypass grafting; $T C D$, transcranial Doppler ultrasonography. 
TABLE 2. Patient perioperative characteristics

\begin{tabular}{|c|c|c|c|c|c|c|}
\hline \multirow[b]{2}{*}{ Characteristic } & \multicolumn{3}{|c|}{ Off-pump CABG } & \multicolumn{3}{|c|}{ On-Pump CABG } \\
\hline & $\overline{C F D}(n=36)$ & Partial clamp $(n=36)$ & $P$ value & Single clamp $(n=34)$ & Double clamp $(n=36)$ & $P$ value \\
\hline Age, $y$, mean \pm SD & $60.8 \pm 10.3$ & $60.6 \pm 9.2$ & .93 & $62.3 \pm 7.8$ & $61.1 \pm 8.6$ & .54 \\
\hline Female sex, n (\%) & $8(22.2)$ & $10(27.8)$ & .59 & $6(17.6)$ & $5(13.9)$ & .67 \\
\hline Caucasian, $\mathrm{n}(\%)$ & $28(77.8)$ & $21(58.3)$ & .08 & $25(73.5)$ & $26(72.2)$ & .90 \\
\hline Diabetes, n (\%) & $18(50.0)$ & $22(61.1)$ & .34 & $13(38.2)$ & $14(38.9)$ & .96 \\
\hline NSTEMI, n (\%) & $17(47.2)$ & $13(36.1)$ & .34 & $7(21.2)$ & $10(28.6)$ & .48 \\
\hline $\mathrm{CCS}$ angina $3 / 4, \mathrm{n}(\%)$ & $19(61.3)$ & $20(57.1)$ & .73 & $21(70.0)$ & $20(62.5)$ & .53 \\
\hline NYHA class III/IV, n (\%) & 0 & $2(5.9)$ & .22 & $2(6.7)$ & $4(12.5)$ & .53 \\
\hline $\mathrm{EF}$, mean $\pm \mathrm{SD}$ & $49.5 \pm 15.1$ & $51.3 \pm 14.4$ & .61 & $52.6 \pm 11.5$ & $52.3 \pm 12.1$ & .93 \\
\hline Renal insufficiency, n (\%) & $2(5.6)$ & $4(11.1)$ & .53 & $4(11.8)$ & $5(13.9)$ & .83 \\
\hline Dyslipidemia, n (\%) & $30(83.3)$ & $32(88.9)$ & .50 & $32(94.1)$ & $29(80.6)$ & .10 \\
\hline Hypertension, n (\%) & $31(86.1)$ & $34(94.4)$ & .27 & $27(79.4)$ & $26(72.2)$ & .48 \\
\hline Smoker, n (\%) & $21(58.3)$ & $15(41.7)$ & .16 & $21(61.8)$ & $14(38.9)$ & .06 \\
\hline Previous PCI, n (\%) & $11(30.6)$ & $11(30.6)$ & 1.00 & $13(38.2)$ & $5(13.9)$ & .02 \\
\hline COPD, n $(\%)$ & $3(8.3)$ & $2(5.6)$ & .75 & $4(11.8)$ & $1(2.8)$ & .17 \\
\hline PVD, n (\%) & $1(2.8)$ & $2(5.6)$ & .68 & $1(2.9)$ & $2(5.6)$ & .68 \\
\hline Diseased vessels, $\mathrm{n}$, mean $\pm \mathrm{SD}$ & $3.1 \pm 0.7$ & $3.0 \pm 0.7$ & .52 & $3.3 \pm 0.8$ & $3.5 \pm 0.8$ & .27 \\
\hline Distal anastomoses, $\mathrm{n}$, mean $\pm \mathrm{SD}$ & $3.2 \pm 0.7$ & $3.0 \pm 0.8$ & .15 & $3.4 \pm 0.7$ & $3.5 \pm 0.8$ & .42 \\
\hline Proximal anastomoses, $\mathrm{n}$, mean $\pm \mathrm{SD}$ & $1.8 \pm 0.6$ & $1.6 \pm 0.6$ & .11 & $2.1 \pm 0.8$ & $2.1 \pm 0.8$ & .98 \\
\hline
\end{tabular}

$C A B G$, Coronary artery bypass grafting; $C F D$, clampless facilitating device; $S D$, standard deviation; NSTEMI, non-ST segment elevation myocardial infarction; CCS, Canadian Cardiovascular Society; NYHA, New York Heart Association; EF, ejection fraction; $P C I$, percutaneous coronary intervention; COPD, chronic obstructive pulmonary disease; $P V D$, peripheral vascular disease.

double-clamp subgroup. Two postoperative strokes occurred in the single-clamp subgroup, compared with none in any of the other subgroups, for an overall stroke rate of $1.4 \%$. Both of these strokes occurred in extubated, stable patients after an initial normal postoperative neurologic exam on postoperative day 1 . The numbers of HITS in these 2 patients (10 and 43) were not outliers compared with the results for other patients. Postoperative atrial fibrillation occurred in 7 patients (19.4\%) in the CFD subgroup, $10(27.8 \%)$ in the partial-clamp subgroup, $6(17.7 \%)$ in the single-clamp subgroup, and $8(22.2 \%)$ in the double-clamp subgroup. The number of patients who received blood transfusions intraoperatively or postoperatively was $2(5.6 \%)$ in the CFD subgroup, $4(11.1 \%)$ in the partial-clamp subgroup, $5(14.7 \%)$ in the single-clamp subgroup, and 6 $(16.7 \%)$ in the double-clamp subgroup. The number of cases of postoperative renal failure was 0 in the CFD subgroup, $1(2.8 \%)$ in the partial-clamp subgroup, 0 in the single-clamp subgroup, and $1(2.8 \%)$ in the double-clamp subgroup. Thirty-day hospital readmission occurred in $3 \mathrm{pa}-$ tients $(8.6 \%)$ in the CFD subgroup, $2(5.7 \%)$ in the partialclamp subgroup, 0 in the single-clamp subgroup, and 3 $(8.3 \%)$ in the double-clamp subgroup.

\section{TCD-Detected Cerebral Embolic Events}

In the on-pump CABG group, TCD data were complete for 33 of $34(97 \%)$ single-clamp patients and 35 of 36
$(97 \%)$ double-clamp patients. In the intention-to-treat analysis, the median number of HITS detected during all periods of aortic manipulation was 10 (IQR, 3-17) for the single-clamp subgroup versus 16 (IQR, 4-49) for the double-clamp subgroup $(P=.10)$ (Figure 2, A).

In the off-pump group, TCD data were complete for 35 of 36 (97\%) partial-clamp patients and 33 of $36(92 \%)$ CFD patients. The median number of HITS detected during all periods of aortic manipulation was 30 (IQR, 22-43) for the CFD subgroup versus 7 (IQR, 0-16) for the partialclamp subgroup $(P<.001)$ (Figure $2, B)$. For patients undergoing off-pump CABG with CFDs for construction of proximal anastomoses, the effect on HITS was positively related to the number of devices used (Figure 3, $A-D$ ).

\section{Neurocognitive Function}

Unfortunately, the exclusion of invalid CNSVS scores reduced the sample sizes available for some analyses. Loss of data due to invalid scores was comparable across the groups, so this factor did not introduce a systematic bias. Using the available valid data, we found no statistically significant between-group differences for any of the CNSVS domain scores preoperatively (Table E1). The groups did differ significantly in the preoperative CNSVS or RBANS Total Score, with the double-clamp subgroup showing higher scores than the other patient subgroups. Thus, the preoperative total score was used as a covariate 
Panel A: On-pump CABG $\mathbf{P}=\mathbf{0 . 1 0}$

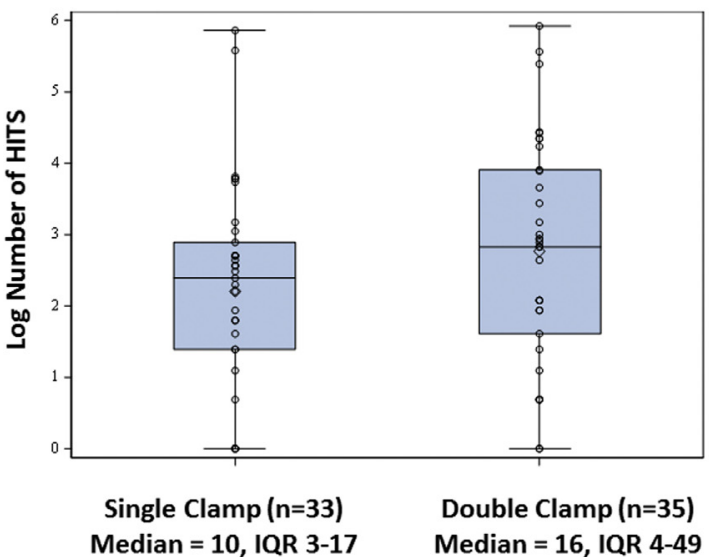

Panel B: Off-pump CABG $P<0.001$

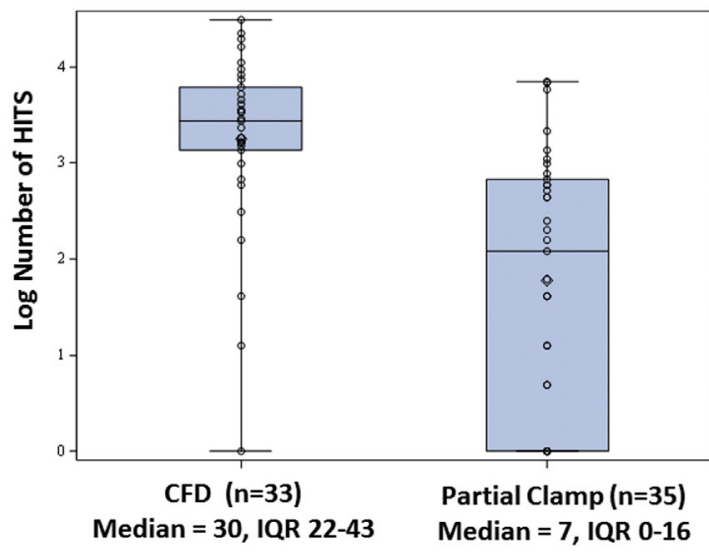

FIGURE 2. Intention-to-treat analysis of HITS data. A, On-pump CABG, single clamp versus double clamp. B, Off-pump CABG, CFD versus partial clamp. The number of HITS was log-transformed to compress the scale for high values and stretch the scale for low values, allowing for a better visual comparison between 2 right-skewed distributions. CABG, Coronary artery bypass grafting; HITS, high-intensity transient signals; IQR, interquartile range; CFD, clampless facilitating device.

in analyses of the corresponding postoperative scores in the on-pump group. In the analysis of both raw and age-adjusted (as well as covariate adjustment for the on-pump group) postoperative and change scores, no comparisons approached statistical significance.

\section{DISCUSSION}

Because of the large number of patients that would be required to demonstrate a difference in a postoperative stroke, a randomized trial with stroke as the primary outcome was impractical. In this study, the number of HITS detected during TCD ultrasonography was used as a surrogate for cerebral embolism and was the primary outcome.

Wolf and coworkers used TCD to detect cerebral microembolization in 42 patients undergoing off-pump CABG. ${ }^{13}$ They found no difference in total microemboli between the CFD group and the partial-clamp group, but there were significantly more solid microemboli in the partial-clamp group. Liu and associates also used TCD in a prospective observational study and found significantly higher numbers of microemboli in patients undergoing on-pump CABG compared with those undergoing off-pump CABG (median number of HITS, 430 vs $2 ; P<.001) .{ }^{12}$ In a randomized study, Motallebzadeh and colleagues reported 1605 embolic signals in on-pump patients compared with 9 in off-pump patients with a partial clamp. ${ }^{14}$ Other studies have been relatively consistent with the foregoing reports. $^{15,16}$

The main findings of this study can be summarized as follows. For patients undergoing $\mathrm{CABG}$ with low-grade aortic disease determined by epiaortic ultrasonography, (1) there was no difference in cerebral embolic events between on-pump patients undergoing a single-clamp technique and those undergoing a double-clamp technique; (2) in off-pump patients, more cerebral embolic events occurred when CFDs were used compared with the partial-clamp technique; and (3) the effect of using CFDs on cerebral embolic events was directly related to the number of devices used. Each insertion and removal of the device, much like with a partial clamp, is associated with some degree of cerebral microembolization. These results also suggest that the use of CFDs is another form of aortic manipulation and might not completely eliminate the risk of cerebral embolism. This study also contradicts previous studies that have reported a benefit from using CFDs in lieu of partial clamping in all off-pump patients.

Observational analyses, ${ }^{17}$ including one from our own institution, ${ }^{18}$ have shown a benefit from minimizing or avoiding aortic manipulation. Emmert and colleagues found a significant reduction in the incidence of stroke $(0.7 \%$ vs $2.3 \%)$ with the use of the CFDs compared with a partial clamp in off-pump patients. ${ }^{19}$

The discrepancies noted between the aforementioned studies and our present study can be explained by several factors. First, the ubiquitous use of epiaortic ultrasound in this trial helped significantly reduce selection bias and confounding based on the burden of aortic disease. Therefore, patients who were selected for the on-pump or off-pump group at the discretion of the operating surgeon and then randomized to the aortic manipulation strategy were more likely to have a similar level of atheroembolic risk compared with patients in observational analyses that account for neither selection bias nor burden of aortic disease. The advantage of CFDs compared with partial clamping that has been observed in other studies may be partially related to their use in 

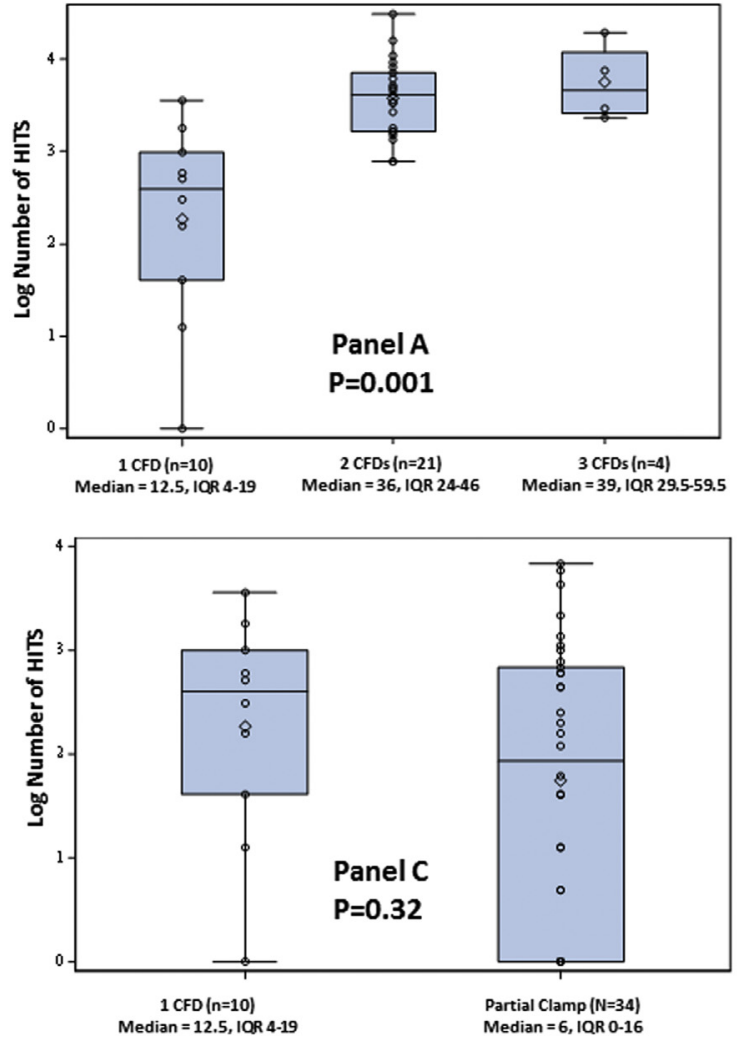
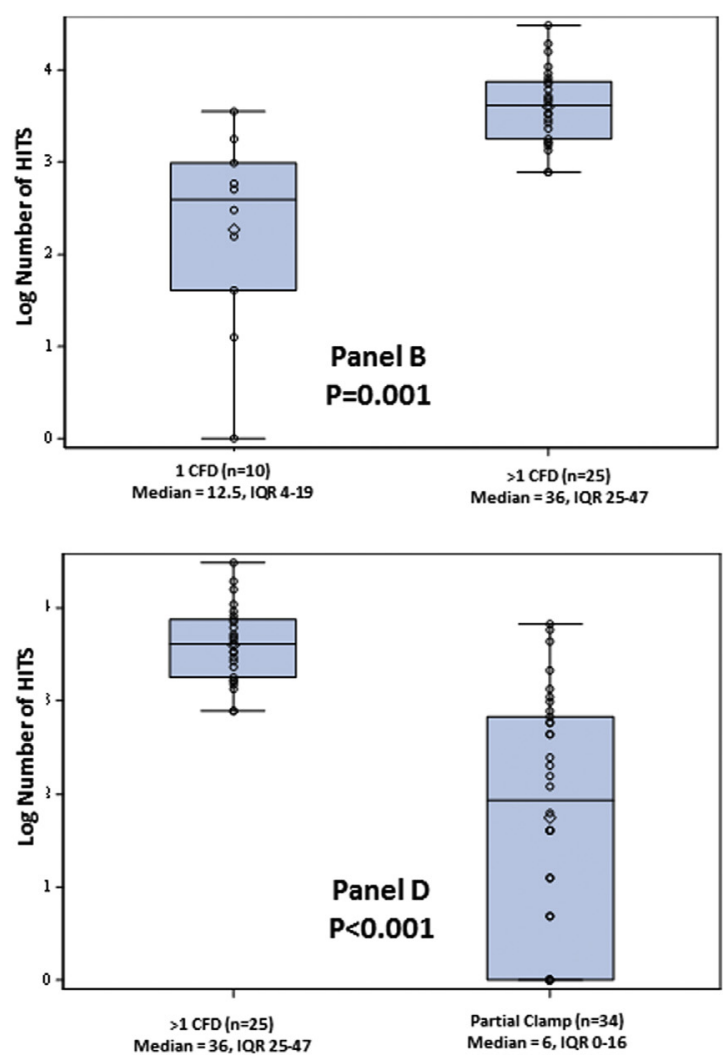

FIGURE 3. As-treated analysis of HITS data in off-pump CABG. A, Number of CFDs used and HITS recorded. B, One CFD versus $>1$ CFDs. C, One CFD versus partial clamp. D, More than 1 CFD versus partial clamp. The number of HITS was log-transformed to compress the scale for high values and stretch the scale for low values, allowing for a better visual comparison between 2 right-skewed distributions. HITS, High-intensity transient signals; CFD, clampless facilitating device; $I Q R$, interquartile range.

patients with varying levels of advanced aortic disease and surgeon selection. In our institution, patients who were identified with advanced aortic disease (epiaortic grade 3-5) were not eligible for randomization, because equipoise does not exist in our practice about how to manage these patients; we do not clamp the aorta and use either CFDs or in situ arterial grafts alone or as inflow for other conduits. Furthermore, there may have been more HITS in the CFD group compared with the partial-clamp group simply because there were more opportunities for measurement, given that 25 patients in the CFD group had multiple CFDs (4 measurement occasions vs 2 in the partial-clamp group).

In addition, because of the intricacies associated with TCD analysis, a dedicated neurologist with expertise in TCD (A.A.) reviewed and adjudicated our TCD findings. Similarly, based on his analysis and previous reports, 5,6 we did not feel that we could accurately separate gaseous emboli from solid emboli in this study. Finally, the randomization of a large number of patients in this study minimized the confounding that may exist in observational retrospective and prospective cohort studies even with the use of advanced statistical analyses, such as propensity-score matching.
Similar to other studies, ${ }^{12,14,20}$ we failed to find a correlation between neurocognitive testing and cerebral microembolization. It is possible that cerebral microemboli that are detected by TCD do not result in persistent neurocognitive dysfunction, and that such properties as size and composition are more important than actual number. ${ }^{21}$

The main limitation of this study was the use of TCD as a surrogate for cerebral adverse events. TCD's limitations are well known and include no proven correlation with adverse neurologic clinical events, difficulty with data capture during surgery, difficulty differentiating artifacts from microembolic events, and difficulty distinguishing gaseous from solid microemboli. The use of diffusion-weighted magnetic resonance imaging would have strengthened this study, but was cost-prohibitive. The use of a dedicated neuropsychometrist to perform neurocognitive testing might have improved the ability to detect subtle differences in cognitive impairment among the groups.

The sample size calculations were derived from TCD data in previously published reports and preliminary data at our own institution (for off-pump CABG). ${ }^{11,12}$ Nonetheless, the number of HITS observed in this study was far lower than anticipated in all of the groups. This 
raises the possibility of a type II error in the on-pump comparison, because the study was not powered to detect a smaller effect size. The likely main reason for the lower number of HITS in all groups was that our TCD recordings were reviewed and adjudicated by a neurologist with expertise in TCD. Many signals that were labeled as HITS by the computer software were in fact false-positive readings.

\section{CONCLUSIONS}

There was no significant difference with the use of 2 clamps compared with 1 clamp for patients undergoing on-pump CABG, and there was no advantage of using CFDs compared with a partial-clamp technique for patients undergoing off-pump CABG. Therefore, for off-pump patients with grade I-II aortic disease requiring aortocoronary proximal anastomoses, we recommend the use of partial clamping, especially when multiple proximal anastomoses are performed. For patients undergoing on-pump CABG, either a single-clamp or a double-clamp strategy can be used in patients with grade I-II aortic disease, depending on surgeon preference.

\section{Conflict of Interest Statement}

M.E.H. serves as a consultant for Maquet Cardiovascular. All other authors have nothing to disclose with regard to commercial support.

\section{References}

1. Filsoufi F, Rahmanian PB, Castillo JG, Bronster D, Adams DH. Incidence, topography, predictors and long-term survival after stroke in patients undergoing coronary artery bypass grafting. Ann Thorac Surg. 2008;85:862-70.

2. Diegeler A, Börgermann J, Kappert U, Breuer M, Böning A, Ursulescu A, et al. Off-pump versus on-pump coronary-artery bypass grafting in elderly patients. $N$ Engl J Med. 2013;368:1189-98.

3. Lamy A, Devereaux PJ, Yusuf S. Off-pump or on-pump coronary-artery bypass grafting. N Engl J Med. 2013;369:196.

4. Goldstein SA, Evangelista A, Abbara S, Arai A, Asch FM, Badano LP, et al. Multimodality imaging of diseases of the thoracic aorta in adults: from the American Society of Echocardiography and the European Association of Cardiovascular Imaging: endorsed by the Society of Cardiovascular Computed Tomography and Society for Cardiovascular Magnetic Resonance. J Am Soc Echocardiogr. 2015;28:119-82.

5. Darbellay GA, Duff R, Vesin JM, Despland PA, Droste DW, Molina C, et al. Solid or gaseous circulating brain emboli: are they separable by transcranial ultrasound? J Cereb Blood Flow Metab. 2004;24:860-8.

6. Markus HS, Punter M. Can transcranial Doppler discriminate between solid and gaseous microemboli? Assessment of a dual-frequency transducer system. Stroke. 2005;36:1731-4
7. Banahan C, Rogerson Z, Rousseau C, Ramnarine KV, Evans DH, Chung EM. An in vitro comparison of embolus differentiation techniques for clinically significant macroemboli: dual-frequency technique versus frequency modulation method. Ultrasound Med Biol. 2014;40:2642-54.

8. Hammon JW, Stump DA, Butterworth JF, Moody DM, Rorie K, Deal DD, et al. Coronary artery bypass grafting with single cross-clamp results in fewer persistent neuropsychological deficits than multiple clamp or offpump coronary artery bypass grafting. Ann Thorac Surg. 2007;84:1174-8; discussion 1178-9.

9. Hammon JW, Stump DA, Butterworth JF, Moody DM, Rorie K, Deal DD, et al. Single crossclamp improves 6-month cognitive outcome in high-risk coronary bypass patients: the effect of reduced aortic manipulation. J Thorac Cardiovasc Surg. 2006;131:114-21.

10. Puskas JD, Stringer A, Hwang SN, Hatfield B, Smith AS, Kilgo PD, et al. Neurocognitive and neuroanatomic changes after off-pump versus on-pump coronary artery bypass grafting: long-term follow-up of a randomized trial. J Thorac Car diovasc Surg. 2011;141:1116-27.

11. El Zayat H, Puskas JD, Hwang S, Thourani VH, Lattouf OM, Kilgo P, et al Avoiding the clamp during off-pump coronary artery bypass reduces cerebral embolic events: results of a prospective randomized trial. Interact Cardiovasc Thorac Surg. 2012;14:12-6.

12. Liu YH, Wang DX, Li LH, Wu XM, Shan GJ, Su Y, et al. The effects of cardiopulmonary bypass on the number of cerebral microemboli and the incidence of cognitive dysfunction after coronary artery bypass graft surgery. Anesth Analg. 2009; 109:1013-22.

13. Guerrieri Wolf L, Abu-Omar Y, Choudhary BP, Pigott D, Taggart DP. Gaseous and solid cerebral microembolization during proximal aortic anastomoses in off-pump coronary surgery: the effect of an aortic side-biting clamp and two clampless devices. J Thorac Cardiovasc Surg. 2007;133:485-93.

14. Motallebzadeh R, Bland JM, Markus HS, Kaski JC, Jahangiri M. Neurocognitive function and cerebral emboli: randomized study of on-pump versus off-pump coronary artery bypass surgery. Ann Thorac Surg. 2007;83:475-82.

15. Scarborough JE, White W, Derilus FE, Mathew JP, Newman MF, Landolfo KP. Combined use of off-pump techniques and a sutureless proximal aortic anastomotic device reduces cerebral microemboli generation during coronary artery bypass grafting. J Thorac Cardiovasc Surg. 2003;126:1561-7.

16. Abu-Omar Y, Balacumaraswami L, Pigott DW, Matthews PM, Taggart DP. Solid and gaseous cerebral microembolization during off-pump, on-pump, and open cardiac surgery procedures. J Thorac Cardiovasc Surg. 2004; 127:1759-65.

17. Misfeld M, Brereton RJ, Sweetman EA, Doig GS. Neurologic complications af ter off-pump coronary artery bypass grafting with and without aortic manipulation: meta-analysis of 11,398 cases from 8 studies. J Thorac Cardiovasc Surg. 2011;142:e11-7.

18. Moss E, Puskas JD, Thourani VH, Kilgo P, Chen EP, Leshnower BG, et al. Avoiding aortic clamping during coronary artery bypass grafting reduces postoperative stroke. J Thorac Cardiovasc Surg. 2015;149:175-80.

19. Emmert MY, Seifert B, Wilhelm M, Grünenfelder J, Falk V, Salzberg SP. Aortic no-touch technique makes the difference in off-pump coronary artery bypass grafting. J Thorac Cardiovasc Surg. 2011;142:1499-506.

20. Van Dijk D, Jansen EW, Hijman R, Nierich AP, Diephuis JC, Moons KG, et al. Cognitive outcome after off-pump and on-pump coronary artery bypass graft surgery: a randomized trial. JAMA. 2002;287:1405-12.

21. van Dijk D, Kalkman CJ. Why are cerebral microemboli not associated with cognitive decline? Anesth Analg. 2009;109:1006-8.

Key Words: CABG, stroke, neurocognitive outcomes 
TABLE E1. Preoperative and postoperative neurocognitive results

\begin{tabular}{|c|c|c|c|c|c|c|}
\hline \multirow[b]{2}{*}{ Cognitive domain } & \multicolumn{3}{|c|}{ Off-pump CABG } & \multicolumn{3}{|c|}{ On-pump CABG } \\
\hline & CFD & Partial clamp & $P$ value & Single Clamp & Double clamp & $P$ value \\
\hline \multicolumn{7}{|c|}{ Psychomotor Speed Scale Score } \\
\hline Preoperative & $86.8 \pm 19.2(\mathrm{n}=15)$ & $86.3 \pm 12.8(\mathrm{n}=15)$ & .94 & $92.1 \pm 17.9(\mathrm{n}=19)$ & $89.1 \pm 20.6(n=23)$ & .58 \\
\hline Postoperative & $94.67 \pm 20.2(\mathrm{n}=12)$ & $98.75 \pm 10(n=16)$ & .52 & $93.29 \pm 19(\mathrm{n}=21)$ & $91.92 \pm 16.3(\mathrm{n}=26)$ & .78 \\
\hline Change & $9.9 \pm 15.8(\mathrm{n}=12)$ & $11.5 \pm 11.5(\mathrm{n}=15)$ & .77 & $3.6 \pm 12.6(\mathrm{n}=18)$ & $3.5 \pm 15.8(\mathrm{n}=22)$ & .98 \\
\hline \multicolumn{7}{|c|}{ Processing Speed Scale Score } \\
\hline Preoperative & $90.4 \pm 16(\mathrm{n}=15)$ & $89.1 \pm 14(\mathrm{n}=20)$ & .80 & $99.3 \pm 14.1(\mathrm{n}=22)$ & $92 \pm 18(\mathrm{n}=27)$ & .11 \\
\hline Postoperative & $94.13 \pm 17.2(n=16)$ & $96.67 \pm 13.4(\mathrm{n}=21)$ & .61 & $103 \pm 16.5(n=24)$ & $98.25 \pm 13.4(\mathrm{n}=28)$ & .26 \\
\hline Change & $5.5 \pm 15.4(\mathrm{n}=15)$ & $9 \pm 11.1(\mathrm{n}=20)$ & .49 & $5.8 \pm 13.6(\mathrm{n}=22)$ & $5.6 \pm 16.9(\mathrm{n}=25)$ & .98 \\
\hline \multicolumn{7}{|c|}{ Complex Attention Scale Score } \\
\hline Preoperative & $89 \pm 22.6(n=12)$ & $79.1 \pm 26.6(\mathrm{n}=11)$ & .36 & $83 \pm 33.9(\mathrm{n}=16)$ & $95.9 \pm 14.3(\mathrm{n}=14)$ & .18 \\
\hline Postoperative & $89.6 \pm 21.4(\mathrm{n}=9)$ & $97.6 \pm 16(n=13)$ & .47 & $96.3 \pm 24.7(n=18)$ & $89.2 \pm 32.5(\mathrm{n}=20)$ & .40 \\
\hline Change & $1 \pm 12.7(\mathrm{n}=6)$ & $15.9 \pm 29.7(\mathrm{n}=9)$ & .23 & $16.6 \pm 29.1(\mathrm{n}=13)$ & $3.1 \pm 10.6(\mathrm{n}=12)$ & .15 \\
\hline \multicolumn{7}{|c|}{ Visual Memory Scale Score } \\
\hline Preoperative & $96.7 \pm 14.3(\mathrm{n}=17)$ & $93.2 \pm 13.6(\mathrm{n}=21)$ & .53 & $91.9 \pm 16.4(\mathrm{n}=22)$ & $94.4 \pm 20.9(\mathrm{n}=25)$ & .60 \\
\hline Postoperative & $95.9 \pm 14.6(\mathrm{n}=15)$ & $95.4 \pm 14.5(\mathrm{n}=19)$ & .94 & $91.79 \pm 15.2(\mathrm{n}=24)$ & $93.9 \pm 19.9(\mathrm{n}=29)$ & .65 \\
\hline Change & $-2.1 \pm 23(\mathrm{n}=15)$ & $1.1 \pm 18.3(\mathrm{n}=19)$ & .62 & $0.59 \pm 16.2(\mathrm{n}=22)$ & $0.13 \pm 17.4(\mathrm{n}=24)$ & .93 \\
\hline \multicolumn{7}{|c|}{ Verbal Memory Scale Score } \\
\hline Preoperative & $89.4 \pm 21.5(\mathrm{n}=17)$ & $80.7 \pm 20(n=20)$ & .21 & $93.1 \pm 20.7(n=22)$ & $87.8 \pm 20.8(\mathrm{n}=25)$ & .39 \\
\hline Postoperative & $84.2 \pm 24.4(\mathrm{n}=17)$ & $85.6 \pm 21.5(\mathrm{n}=20)$ & .81 & $94 \pm 19.1(\mathrm{n}=24)$ & $92 \pm 21.2(\mathrm{n}=30)$ & .96 \\
\hline Change & $-5.1 \pm 24.5(\mathrm{n}=17)$ & $3.3 \pm 14(\mathrm{n}=19)$ & .20 & $2 \pm 13.8(\mathrm{n}=22)$ & $3.7 \pm 23.1(\mathrm{n}=25)$ & .77 \\
\hline \multicolumn{7}{|c|}{ Cognitive Flexibility Scale Score } \\
\hline Preoperative & $89.4 \pm 14.2(\mathrm{n}=12)$ & $82.8 \pm 26.8(\mathrm{n}=12)$ & .41 & $89.6 \pm 18.4(\mathrm{n}=16)$ & $90.9 \pm 17.5(\mathrm{n}=18)$ & .84 \\
\hline Postoperative & $91.2 \pm 15.2(\mathrm{n}=11)$ & $98 \pm 17.1(\mathrm{n}=14)$ & .38 & $96.7 \pm 21.3(\mathrm{n}=20)$ & $95.7 \pm 19.9(\mathrm{n}=20)$ & .87 \\
\hline Change & $1.9 \pm 9.4(\mathrm{n}=8)$ & $14.1 \pm 25(n=9)$ & .08 & $11.1 \pm 7.6(\mathrm{n}=14)$ & $9.4 \pm 11.3(\mathrm{n}=15)$ & .75 \\
\hline \multicolumn{7}{|c|}{ Executive Function Scale Score } \\
\hline Preoperative & $89.2 \pm 13.1(\mathrm{n}=13)$ & $83.7 \pm 26(n=14)$ & .47 & $94.8 \pm 19.1(\mathrm{n}=19)$ & $89.2 \pm 18.3(\mathrm{n}=23)$ & .36 \\
\hline Postoperative & $84.3 \pm 16.7(\mathrm{n}=13)$ & $83.6 \pm 25.1(\mathrm{n}=15)$ & .93 & $88.6 \pm 24.3(\mathrm{n}=20)$ & $86.2 \pm 21.9(\mathrm{n}=22)$ & .74 \\
\hline Change & $5.7 \pm 10.6(\mathrm{n}=11)$ & $10.5 \pm 20.5(\mathrm{n}=11)$ & .40 & $8.6 \pm 7.8(\mathrm{n}=17)$ & $7.8 \pm 12.5(\mathrm{n}=20)$ & .85 \\
\hline
\end{tabular}

$C A B G$, Coronary artery bypass grafting; $C F D$, clampless facilitating device. 